\title{
Pengaruh Perbedaan Umpan Buatan (Artificial bait) Terhadap Hasil Tangkapan Dengan Pancing Coping (Hand line) Di Perairan Desa Daeo Majiko Kabupaten Pulau Morotai
}

\author{
(The Effect of Differences in Artificial Bait on Catches by Fishing Coping \\ (Hand line) in the Waters of the Village of Daeo Majiko, Morotai Island Regency) \\ Djainudin Alwi ${ }^{*}$ dan Sandra Hi. Muhammad ${ }^{2}$ \\ ${ }^{1}$ Program Studi Ilmu Kelautan, FPIK-UNIPAS, Morotai \\ ${ }^{2}$ Program Studi Ilmu Kelautan, FPIK-UNIPAS Morotai \\ E-mail.djainudinalwi@gmail.com
}

\begin{abstract}
ABSTRAK
Secara umum nelayan di Kabupaten Pulau Morotai dalam memanfaatkan sumberdaya ikan masih bersifat tradisional, rata-rata nelayan masih mengunakan alat tangkap yang sederhana dengan menggunakan umpan alami sebagai pemikat ikan dalam operasi penangkapan ikan tuna dan cakalang. Penelitian ini diharapkan dapat memberikan informasi ilmiah dan juga sebagai bahan pertimbangan dalam menentukan kebijakan pengembangan teknologi perikanan tangkap yang ramah lingkungan. Sementara manfaat lain yang ingin diperoleh yaitu memberikan informasi kepada nelayan tentang penggunaan umpan buatan (artificial bait) sebagai umpan alternatif, untuk itu tujuan penelitian ini yaitu; 1) Membandingkan hasil tangkapan ikan berdasarkan jenis umpan buatan yang digunakan dan; 2) Mempelajari pengaruh perbedaan jenis umpan buatan terhadap hasil tangkapan dengan pancing coping (hand line).

Penelitian ini berlokasi di Perairan Desa Daeo Majiko Kabupaten Pulau Morotai. Waktu pelaksanaan pada bulan Juni-September 2019.Penelitian ini dilakukan dengan menggunakan metode eksperimental fishing yaitu pembuatan perlakuan yang diujicobakan untuk memperoleh informasi tentang persoalan yang diteliti. Data dianalisis dengan menggunakan analisis keragaman ANOVA satu arah (one way anova), analisis respon yang dilihat ialah nilai rata-rata dari pengulangan setiap perlakuan.Hasil penelitian menunjukan bahwa terdapat 5 jenis ikan yang tertangkap selama operasi penangkapan yakni; tuna sirip kuning (Thunus albacares), cakalang (Katsuwonus pelamis), tongkol (Auxis thazard), selayang (Elagatis bipinnulata) dan Lemadang (Coryphaena hippurus). Jumlah total hasil tangkapan pada masing-masing perlakuan selama penelitian menunjukkan bahawa perlakuan UB1(Almunium) relatif lebih banyak yaitu sebesar $348 \mathrm{~kg}$ dibandingkan dengan 2 (dua) perlakuan lainnya masing-masing UB2 (serat sutera) sebesar $292 \mathrm{~kg}$ dan UB3(Kepingan CD) sebesar $128 \mathrm{~kg}$. Hasil uji ANOVA satu arah (one way anova) menunjukan bahwa perbedaan umpan buatan berpengaruh nyata terhadap jumlah berat hasil tangkapan.
\end{abstract}

Kata kunci : Umpan buatan, pancing coping, hasil tangkap 


\section{ABSTRACT}

In general, fishermen in Morotai Island Regency in utilizing fish resources are still traditional, on average fishermen still use simple fishing gear using natural bait Like a fish attractor in tuna and skipjack fishing operations. This research is expected to provide scientific information and also as a material for consideration in determining policies for the development of environmentally friendly capture fisheries technology. While other benefits to be obtained are to providing information to fishermen about the use of artificial bait (artificial bait) as an alternative bait.The aim of this research was;1) to compare fish catches based on the type of artificial bait used and; 2) To study the effect of different types of artificial bait on catches with a fishing rod coping (handline).

This research is located in the waters of Daeo Majiko Village, Morotai Island Regency. The implementation time is from June to September 2019. This research was conducted using the experimental fishing method, namely the making of treatments that were tested to obtain information about the problem under study. Data were analyzed using one way ANOVA diversity analysis, the response analysis was the average value of repetition of each treatment. The results showed that there were five types of fish caught during the fishing operation namely; yellowfin tuna (Thunus albacares), skipjack (Katsuwonus pelamis), cob(Auxis thazard), Selayang (Elagatis bipinnulata) and Lemadang (Coryphaena hippurus). The total number of catches in each treatment during the study showed that UBI (Aluminum) treatment was relatively more in the amount $348 \mathrm{~kg}$ compared to 2 (two) other treatments, namely each UB2 (silk fiber) was $292 \mathrm{~kg}$ and UB3(CD) was $128 \mathrm{~kg}$. One way ANOVA test results show that the difference in artificial bait significantly affects the weight of the catch.

Keywords : Artificial bait, fishing coping, fish catches 


\section{PENDahuluan}

Kabupaten Pulau Morotai merupakan kabupaten bahari, hal ini terbukti dari keadaan geografisnya yang berupa kepulauan dimana $89 \%$ desa yang terdapat di Kabupaten Pulau Morotai merupakan desa pesisir sehingga daerah ini kaya akan potensi sumberdaya alam laut khususnya sumberdaya ikan. Hasil Produksi perikanan khususnya perikanan tangkap di Kabupaten Pulau Morotai terus meningkat setiap tahunnya dan pada tahun 2014 mencapai 16.198 ton dengan kenaikan 17 persen dari tahun sebelumnya tercatat hasil produksi ikan dengan berbagai jenis seperti tuna, deho, layang, tongkol, cakalang, ikan demersal, teri, dolosi, julung dan jenis lainya. (BPS Provinsi Maluku Utara, 2014).

Umpan merupakan salah satu faktor yang sangat besar pengaruhnya terhadap keberhasilan dalam usaha penangkapan baik masalah jenis umpan, sifat umpan maupun cara ikan memakan umpan. Menurut Leksono, (1983) membagi jenis-jenis umpan berdasarkan kondisi umpan tersebut, yaitu umpan hidup (live bait) dan umpan mati (dead), sedangkan menurut sifatnya dibagi menjadi umpan alami (natural bait) dan umpan buatan (artificial bait). Tingkah laku ikan yang dimanfaatkan dalam perikanan pancing adalah rangsangan yang muncul secara internal maupun eksternal. Secara internal ransangan terhadap makanan sedangkan secara eksternal rangsangan ditimbukan oleh bau,warna, bentuk dan pergerakan umpan yang digunakan.

Secara umum nelayan di Kabupaten Pulau Morotai dalam memanfaatkan sumberdaya ikan masih bersifat tradisional, sebagaian besar nelayan masih mengunakan alat tangkap yang sederhana dan menggunakan umpan alami sebagai pemikat ikan dalam operasi penangkapan ikan tuna dan cakalang. Olehnya itu berdasarkan pemikiran dan pengembangan perikanan pancing kedepan maka tujuan penelitian ini ialah 1) Membandingkan hasil tangkapan ikan berdasarkan jenis umpan buatan yang digunakan dan; 2) Mempelajari pengaruh perbedaan jenis umpan buatan terhadap hasil tangkapan dengan pancing coping (hand line). Sedangkan manfaat dari penelitian ini diharapkan dapat memberikan informasi ilmiah dan juga sebagai bahan pertimbangan dalam menentukan kebijakan pengembangan teknologi perikanan tangkap yang ramah lingkungan. Sementara manfaat lain yang ingin diperoleh yaitu memberikan informasi kepada nelayan tentang penggunaan umpan buatan (artificial bait) sebagai umpan alternatif.

\section{Metodologi Penelitian \\ 2.1 Waktu dan Tempat}

Penelitian ini dilaksanakan pada bulan Juni-September 2019. Lokasi penelitian ini di Perairan Desa Daeo Majiko Kabupaten Pulau Morotai dengan posisi geografis 010 $5631.7^{\prime \prime}$ LS. ${ }^{0} 128 . ' 32.5$ "BT.

\subsection{Posedur Penelitian}

Penelitian ini dilakukan dengan menggunakan metode eksperimental fishing yaitu pembuatan perlakuan yang diujicobakan untuk memperoleh informasi tentang persoalan yang diteliti. Dengan metode ini dapat diperoleh informasi yang diperlukan dalam melakukan penelitian tentang persoalan yang akan dibahas sehingga akan dihasilkan suatu kesimpulan sesuai dengan tujuan penelitian ( Sudjana, 1994).

\subsection{Pengumpulan Data}

Teknik pengumpulan data untuk mendekati tujuan pertama yang telah ditetapkan, yaitu mempelajari pengaruh perbedaan jenis umpan buatan terhadap hasil tangkapan dengan pancing coping (hand line). Penelitian dilakukan dengan pengamatan langsung dan tidak langsung. 
Pengamatan langsung merupakan data primer yaitu pengamatan selama operasi penangkapan ikan, sedangkan data sekunder melalui studi pustaka.

\subsection{Teknik Analisis Data}

1) Analisis data hasil tangkapan

Data jumlah hasil tangkapan (kg) dari ketiga jenis umpan yang digunakan ditabulasi menurut perlakuan dan trip operasi kemudian dianalisis secara diskriptif.

2) Analisis pengaruh perlakuan

Perlakuan yang akan diuji ada tiga, yakni perlakuan umpan Almunium (UB $\mathbf{U}_{1}$ ), Serat sutera $\left(\mathbf{U B}_{2}\right)$ dan Kepingan $\mathrm{CD}\left(\mathbf{U B}_{3}\right)$. Analisis respons yang akan digunakan ialah nilai ratarata dari ulangan dalam perlakuan.

Hipotesis yang digunakan dalam penelitian ini :

$\mathrm{H}_{0}$ : Tidak ada perbedaan yang nyata antara rata-rata hitung hasil tangkapan dari perlakuan jenis umpan $\left(\mathrm{UB}_{1}, \mathrm{UB}_{2}\right.$ dan $\left.\mathrm{UB}_{3}\right)$

$\mathrm{H}_{1}$ : Ada perbedaan yang nyata antara rata-rata hitung hasil tangkapan dari perlakuan jenis umpan $\left(\mathrm{UB}_{1}, \mathrm{UB}_{2}\right.$ dan $\left.\mathrm{UB}_{3}\right)$

Selanjutnya untuk menguji hipotesis tersebut, maka dilakukan analisis keragaman (ANOVA) dengan satu arah (one way anova) menurut Yunigunarto dalam Alwi,et al.(2014), dengan taraf nyata $5 \%$ dengan model matematis sebagai berikut :

1) Jumlah kuadrat perlakuan(SST)

$$
\mathrm{SST}=\sum\left[\frac{T c^{2}}{n_{2}}\right]-\frac{\left(\sum x\right)^{2}}{N}
$$

2) Jumlah kuadrat kesalahan (SSE)

$$
\mathrm{SSE}=\sum(x)^{2}-\sum\left[\frac{T c^{2}}{n_{c}}\right]
$$

3) KeragamanTotal (SS total)

$$
\mathrm{SS} \text { total }=\mathrm{SST}+\mathrm{SSE}
$$

Dimana $: \mathrm{Tc}=$ Total kolom

$\mathrm{nc}=$ Jumlah ulangan

$\mathrm{N}=$ Jumlah total ulangan dalam perlakuan

$\Sigma \mathrm{X}^{2}=$ Jumlah kuadrat perlakuan

\section{HASIL DAN PEMBAHASAN}

\subsection{Komposisi Jenis Hasil Tangkapan}

Penelitian dengan menggunakan 3 (tiga) jenis perlakuan umpan yang berbeda operasi penangkapan dengan dengan menggunakan pancing coping (handline) selama 9 (sembilan) kali trip penangkapan menghasilkan data tangkapan berupa komposisi jenis, jumlah dan berat hasil tangkapan. Data komposisi jenis ikan yang tertangkap disajikan pada tabel 1 dibawah ini :

Tabel. 1 Komposisi Jenis Hasil Tangkapan 
JURNAL ILMU KELAUTAN KEPULAUAN, 2 (2) ;23-31, DESEMBER 2019

\begin{tabular}{|c|c|c|c|c|c|}
\hline \multirow[b]{2}{*}{ No } & \multicolumn{3}{|c|}{ Jenis Ikan } & \multicolumn{2}{|c|}{ Hasil tangkapan } \\
\hline & $\begin{array}{l}\text { Nama } \\
\text { Lokal }\end{array}$ & $\begin{array}{l}\text { Nama } \\
\text { Indonesia }\end{array}$ & $\begin{array}{l}\text { Nama } \\
\text { Ilmiah }\end{array}$ & $\begin{array}{l}\text { Jumlah } \\
\text { (ekor) }\end{array}$ & $\begin{array}{c}\text { Berat } \\
(\mathrm{kg})\end{array}$ \\
\hline 1 & Madadihang & $\begin{array}{l}\text { Tuna sirip } \\
\text { kuning }\end{array}$ & Thunus albacares & 145 & 505 \\
\hline 2 & Cakalang & Cakalang & Katsuwonus pelamis & 57 & 165 \\
\hline 3 & Komo & Tongkol & Auxis thazard & 15 & 46 \\
\hline 4 & Suru & Selayang & Elagatis bipinnulata & 15 & 39 \\
\hline 5 & Maluari & Lemadang & Coryphaena hippurus & 13 & 4 \\
\hline \multicolumn{4}{|c|}{ Jumlah Total } & 245 & 759 \\
\hline
\end{tabular}

Sumber : Data olahan 2019

Terdapat 5 jenis ikan yang tertangkap selama penelitian berlangsung, yakni jenis tuna sirip kuning (Thunus albacares),cakalang (Katsuwonus pelamis), tongkol (Auxis thazard), selayang (Elagatis bipinnulata) dan Lemadang (Coryphaena hippurus) dari kelima jenis ikan ini yang merupakan ikan target yaitu ( tuna sirip kuning, cakalang dan tongkol) sedangkan dua jenis lainnya yaitu ikan selayang dan lemadang adalah jenis tangkapan sampingan. Berdasarkan data yang diperoleh jumlah seluruh hasil tangkapan sebanyak 245 ekor dengan berat total sebesar 759 $\operatorname{kg}$ (Tabel 1).

\subsection{Jumlah Hasil Tangkapan berdasarkan Jenis Ikan}

Jumlah hasil tangkapan terbanyak ialah 100 ekor dengan berat total tangkapan $348 \mathrm{~kg}$ yang diperoleh pada penangkapan denga menggunakan umpan buatan dari bahan almunium (UB1), 84 ekor dengan berat $292 \mathrm{~kg}$ tertangkap dengan menggunakan umpan buatan berbahan serat sutera (UB2) sedangkan hasil tangkapan terendah diperoleh dengan menggunakan umpan buatan berbahan dasar kepingan CD (UB3) sebanyak 52 ekor dengan berat $128 \mathrm{~kg}$ (Tabel 2). Data berat hasil tangkapan pada masing-masing perlakuan ini selanjutnya akan dianalisis dengan model matematis ANOVA satu arah (one way anova) untuk melihat sejauhmana pengaruh perlakuan umpan buatan ini terhadapa hasil tangkapan.

Tabel 2. Data hasil tangkapan berdasarkan jenis ikan pada masing-masing perlakuan umpan

Hasil tangkapan/Jenis umpan

\begin{tabular}{cccccccc}
\cline { 3 - 8 } No & Jenis Ikan & \multicolumn{2}{c}{ UB1 (Almunium) } & \multicolumn{2}{c}{ (UB2 (Serat Sutra) } & \multicolumn{2}{c}{ UB3 (Kepingan CD) } \\
\cline { 3 - 8 } & & $\begin{array}{c}\text { Jumlah } \\
\text { (ekor) }\end{array}$ & $\begin{array}{c}\text { Berat } \\
\text { (Kg) }\end{array}$ & $\begin{array}{c}\text { Jumlah } \\
\text { (ekor) }\end{array}$ & $\begin{array}{c}\text { Berat } \\
\text { (Kg) }\end{array}$ & $\begin{array}{c}\text { Jumlah } \\
\text { (ekor) }\end{array}$ & Berat (Kg) \\
\hline 1 & Tuna sirip kuning & 64 & 225 & 63 & 233 & 18 & 47 \\
2 & Cakalang & 25 & 89 & 18 & 48 & 14 & 28 \\
3 & Tongkol & 9 & 28 & 2 & 7 & 4 & 11 \\
4 & Selayang & 2 & 6 & 0 & 0 & 13 & 33 \\
5 & Lemadang & 0 & 0 & 1 & 4 & 3 & 9 \\
\hline & Jumlah & $\mathbf{1 0 0}$ & $\mathbf{3 4 8}$ & $\mathbf{8 4}$ & $\mathbf{2 9 2}$ & $\mathbf{5 2}$ & $\mathbf{1 2 8}$ \\
\hline & Rata-rata & $\mathbf{2 0}$ & $\mathbf{6 9 . 6}$ & $\mathbf{1 6 . 8}$ & $\mathbf{5 8 . 4}$ & $\mathbf{1 0 . 4}$ & $\mathbf{2 5 . 6}$ \\
\hline
\end{tabular}

Sumber : Data olahan 2019 
Gambar 1 menunjukkan bahwa jenis ikan hasil tangkapan didominasi oleh ikan tuna sirip kuning (Thunus albacares) disemua perlakuan umpan, untuk perlakuan UB1 (almunium) tertangkap sebanyak 64 ekor dengan proporsi sebesar (64\%) dan total berat sebesar $225 \mathrm{~kg}$, perlakuan UB2 (serat sutera) sebanyak 63 ekor proporsi $(75 \%)$ dengan total berat sebesar $223 \mathrm{~kg}$ dan untuk perlakuan UB3 (Kepingan CD) jenis ikan tuna sirip kuning (Thunus albacares) yang tertangkap 18 ekor (34\%) dengan berat total sebesar $47 \mathrm{~kg}$. Sedangkan hasil tangkapan terendah pada masing-masing perlakuan umpan yakni jenis ikan lemadang (Coryphaena hippurus) dan ikan selayang (Elagatis bipinnulata) dimana proporsi masing-masing perlakuan yakni UB1 (Almunium) jenis ikan selayang (Elagatis bipinnulata) dengan proporsi (2\%) dan berat total sebesar $6 \mathrm{~kg}$ dan UB2 (serat sutera), jenis lemadang (Coryphaena Hippurus) (1\%) berat total $4 \mathrm{~kg}$, sedangkan UB3 (Kepingan CD) lemadang Coryphaena Hippurus)dengan proporsi (1\%) berat total sebesar $6 \mathrm{~kg}$.
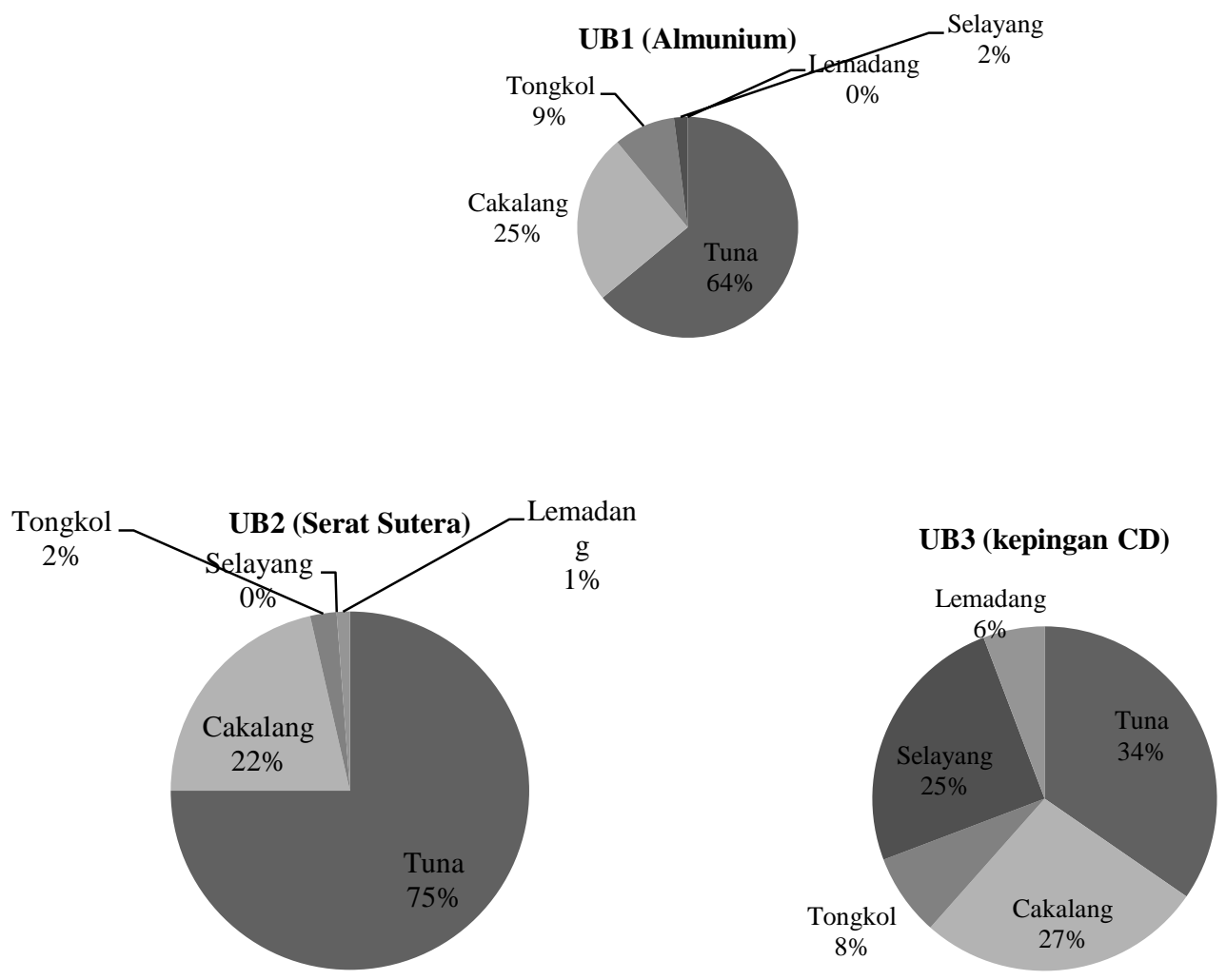

Gambar 1. Presentase jumlah dan jenis ikan hasil tangkapan berdasarkan perlakuan umpan Sumber : Data olahan 2019

\subsection{Jumlah total hasil tangkapan (kg) pada perlakuan umpan dan trip operasi}

Jumlah total hasil tangkapan pada masing-masing perlakuan selama 9 (sembilan) kali trip penangkapan (tabel 3) menunjukkan perlakuan UB1(almunium) relatif lebih banyak yaitu sebesar $348 \mathrm{~kg}$ dibandingkan dengan 2 (dua) perlakuan lainnya masing-masing untuk umpan UB2 (serat sutera) sebesar $292 \mathrm{~kg}$ dan UB3 sebesar $128 \mathrm{~kg}$. 
Tabel 3. Jumlah hasil tangkapan (kg) berdasarkan perlakuan umpan dan trip operasi

\begin{tabular}{cccc}
\hline \multirow{2}{*}{ No } & \multicolumn{3}{c}{ Perlakuan Umpan } \\
\cline { 2 - 4 } & UB1 & UB2 & UB3 \\
\hline 1 & 65 & 40 & 25 \\
2 & 37 & 64 & 22 \\
3 & 49 & 36 & 9 \\
4 & 27 & 47 & 6 \\
5 & 60 & 44 & 16 \\
6 & 78 & 18 & 13 \\
7 & 8 & 11 & 9 \\
8 & 9 & 14 & 9 \\
9 & 15 & 18 & 19 \\
\hline Jumlah Total & $\mathbf{3 4 8}$ & $\mathbf{2 9 2}$ & $\mathbf{1 2 8}$ \\
\hline Rata-rata & $\mathbf{3 8 . 7}$ & $\mathbf{3 2 . 4}$ & $\mathbf{1 4 . 2}$ \\
\hline
\end{tabular}

Sumber: Data olahan 2019

Perbedaan jenis, jumlah dan berat dari setiap tangkapan dengan menggunakan umpan buatan yang berbeda lebih disebabkan oleh pengaruh fisik dari perlakuan umpan tersebut. Perlakuan UB1 (Almunium) mendapatkan hasil tangkapan terbanyak terutama dari jenis tuna dan cakalang karena bentuk fisiknya mengkilat jika digerakan didalam air, sehingga mempengaruhi penglihatan ikan untuk segera menyambar umpan tersebut. Hal ini senada dengan hasil penelitan yang dilakukan oleh Tauladani, et al.(2013) bahwa umpan buatan dengan bahan dasar dari kantong plastik mengkilat mampu menangkap ikan dalam jumlah yang lebih banyak dibandingkan dengan umpan alami dan mayoritas ikan yang tertangkap oleh umpan buatan tersebut adalah ikan tuna sirip kuning atau madidihang. Hal ini diperkirakan terkait dengan visibility atau kemampuan penglihatan dari ikan jenis tersebut.

Kurnia,et al.(2015) menyatakan bahwa tuna adalah salah satu jenis ikan yang memiliki super vision atau kemampuan melihat yang lebih baik dibandingkan dengan jenis ikan yang lain. Ditemukan bahwa ikan-ikan predator laut dalam, seperti tuna, layaran, dan hiu, mampu menjaga kehangatan suhu mata dan otak mereka sehingga memiliki penglihatan yang sangat baik pada saat berburu mangsa. Dengan menjaga mata mereka tetap hangat di dalam perairan yang bersuhu rendah, ikan-ikan predator tersebut dapat melihat 10 kali lebih baik dibanding ikan mangsanya.

Umpan buatan yang terbuat dari bahan-bahan mengkilat memiliki kemampuan untuk memantulkan cahaya yang bisa ditangkap oleh mata tuna. Ikan jenis tuna dan cakalang adalah jenis ikan pelagi besar dan memiliki sensitivitas terhadap cahaya. Tauladani,et al.(2013). Hal ini sejalan dengan kenyataan bahwa selama penelitian pengoperasian alat tangkap dilaksanakan pada siang hari sehingga senantiasa tersedia sumber cahaya yang dapat dipantulkan oleh umpan buatan tersebut. Diduga ikan-ikan target tertarik dengan kilauan cahaya yang dipantulkan oleh umpan buatan. Sangat memungkinkan pula ikan target mengira bahwa kilauan pantulan cahaya dari umpan tersebut berasal dari bagian tubuh ikan mangsanya yang rata-rata berwarna keperakan.

Umpan buatan dengan bahan dasar serat sutera (UB2) merupakan salah satu jenis umpan yang juga disukai oleh ikan tuna, hal ini terbukti dengan jumlah hasil tangkapan yang diperoleh terbanyak kedua setelah umpan buatan dari bahan almunium (UB1), nelayan sering 
mengkombinasikan jenis umpan ini, kelebihan dari umpan jenis ini adalah warna dan bentuk yang dihasilkan. Senada dengan itu menurut (Fuah,et al. 2019). Warna umpan buatan merupakan salah satu komponen yang tidak dapat dipisahkan dari faktor penentu keberhasilan dalam penangkapan ikan dengan menggunakan alat tangkap pancing. Penggunaan warna umpan lebih diutamakan untuk memberikan pengaruh terhadap penglihatan dari ikan target. Berbagai jenis warna umpan sering digunakan dalam penelitian-penelitian, terutama penggunaan warna pada umpan buatan, hal ini dimaksudkan agar dapat memberikan pengaruh bagi penglihatan ikan, karena umpan buatan biasanya tidak memiliki ciri khusus seperti umpan hidup pada umumnya yaitu bau.

Pada dasarnya para nelayan sudah mengetahui tingkah laku atau kebiasaan makan (behavior) dari ikan-ikan yang menjadi target tangkapan mereka sehingga pengunaan umpan khususnya umpan buatan juga disesuaikan dengan kebiasan makan ikan tersebut. Keberhasilan dari alat tangkap berumpan sangat ditentukan oleh aktivitas hidup ikan dalam hal mencari menangkap makanan, pengetahuan yang diperoleh melalui studi tentang tingkah laku atau cara ikan mengambil makanan, akan sangat membantu untuk memahami interaksi spesies target dengan alat tangkap berumpan (Lokkeborrg, 1992).

UB3 (kepingan CD) merupakan jenis umpan paling sedikit hasil tangkapannya, hal ini disebabkan karena bahan dasar umpan ini sangat rapuh dan mudah rusak sehingga penggunaannya tidak efektif, meski demikian kelima jenis ikan (tuna, cakalang, tongkol, selayang dan lemadang) semuanya tertangkap dengan menggunakan jenis umpan ini. Menandakan bahwa umpan jenis ini, berpeluang untuk dijadikan sebagai umpan alternatif, namun bahan dasarnya harus didesain sedemikian rupa agar tahan lama tidak muda rusak jika dimakan oleh ikan.

Berdasarkan data yang telah disajikan, diperoleh bahwa ada perbedaan jumlah dan berat hasil tangkapan dari perlakuan umpan buatan yang digunakan, dimana perlakuan umpan UB1 (Almunium) lebih banyak menangkap ikan dibandingkan dengan perlakuan umpan UB2 (Serat sutera) dan UB3 (Kepingan CD). Hasil uji ANOVA satu arah (one way anova) menunjukan bahwa perbedaan umpan buatan berpengaruh nyata terhadap jumlah berat hasil tangkapan. Hal ini terlihat dari distribusi nilai $\mathrm{F}_{\mathrm{Hit}}(4.1)>\mathrm{F}_{\mathrm{tab}}$ (3.4) dengan taraf nyata $5 \%$, ini berarti bahwa hipotesis $\mathrm{H}_{1}$ diterima dan $\mathrm{H}_{0}$ ditolak.

\section{Kesimpulan}

Hasil penelitian menunjukan bahwa :

1. Terdapat 5 jenis ikan yang tertangkap selama operasi penangkapan yakni; tuna sirip kuning (Thunus albacares),cakalang (Katsuwonus pelamis), tongkol (Auxis thazard), selayang (Elagatis bipinnulata) dan Lemadang (Coryphaena hippurus). Jumlah total hasil tangkapan pada masing-masing perlakuan selama penelitian menunjukkan bahawa perlakuan UB1(Almunium) relatif lebih banyak dibandingkan dengan 2 (dua) perlakuan lainnya.

2. Hasil uji ANOVA satu arah (one way anova) menunjukan bahwa perbedaan umpan buatan berpengaruh nyata terhadap jumlah berat hasil tangkapan 


\section{Ucapan Terima Kasih}

Ucapan Terimakasih tak terhingga penulis sampaikan pada pihak-pihak yang berperan dalam pelaksanaan penelitian ini antara lain:

1. KEMENRISTEK DIKTI sebagai pemberi dana

2. PimpinanUniversitas Pasifik Morotai dan jajarannya atas dukungan moril yang diberikan kepada penulis selama penelitian berlangsung.

3. Team pengambilan data dan para nelayan Desa Daeo majiko Kecamatan Morotai Selatan yang telah meluangkan waktu membantu penulis dalam pengambilan data dilapangan.

\section{Daftar Pustaka}

Alwi, D. Kaparang F.E dan Patty W 2014. Study on the use of different light intensities on fish catch of raft liftnet in Dodinga Bay, West Halmahera Regency. Aquatic Science \& Management, Vol. 2, No. 2, 38-43 ISSN 2337-4403 e-ISSN 2337-5000 jasm-pn00054 Pascasarjana, Universitas Sam Ratulangi.

BPS. Provinsi Maluku Utara, 2014. Maluku Utara Dalam Angka.

Fuah, R.W, Diniah, Puspito G, 2019. Pengaruh Jenis dan warna umpan buatan rawai tegak terhadap hasil tangkapan ikan pelagis kecil Jurnal ALBACORE P-ISSN 2549-1326, EISSN 2655-559X Volume 3, No 1, Hal 025-034

Kurnia M, Sudirman, Yusuf, M. 2015.Pengaruh Perbedaan Ukuran Mata Pancing Terhadap Hasil Tangkapan Pancing Ulur Di Perairan Pulau Sabutung Pangkep. Jurnal Marine Fisheries ISSN 2087-4235 Vol. 6, No. 1, Hal: 87-95.

Leksono, U. 1983. Suatu Studi Tentang Penggunaan Ikan Lemuru Sebagai Umpan Pada Perikanan Rawai Tuna di PT. Pelabuhan Samudera Besar Benoa, Bali. Fakultas Perikanan Institut Pertanian Bogor. 101 hal.

Lokkerborg S. Jhon and Nessen T. 1992. The Importance of Chemical Stimuli in Bait Fishing Trials With Presoaked Bait. Fish Res., 14, 21-9.

Sudjana, N. 1994. Desain dan Analisis Eksperimen. Edisi III. Tarsito Bandung

Tauladani S. A. Arifin M. Z, and Wijaya. N 2013. Pengaruh umpan buatan dan umpan alami terhadap hasil tangkapan tuna hand line di perairan Laut Maluku. Aquatic Science \& Management, Edisi Khusus 1, 57-61 (Mei 2013) Pascasarjana, Universitas Sam Ratulangi. 